\title{
KOMPETENSI SUMBER DAYA MANUSIA DALAM ERA TEKNOLOGI: ANALISIS TERHADAP PEGAWAI DI LINGKUNGAN PEMERINTAHAN
}

\author{
1Suhaya, ${ }^{2}$ Jarnawi Afgani Dahlan, ${ }^{3}$ Afriani \& ${ }^{4}$ Siti Sohibah \\ 1, 3,4 Universitas Islam Syekh-Yusuf Tangerang \\ ${ }^{2}$ Universitas Pendidikan Indonesia \\ Email: suhaya@unis.ac.id
}

\begin{abstract}
ABSTRAK
Tujuan dalam penelitian ini adalah mengkaji perbedaan kompetensi dalam kognitif, afektif, dan psikomotor sumber daya manusia dalam teknologi informasi, mengkaji hubungan antara kompetensi dalam teknologi informasi dengan pengelolaan informasi; kebutuhan akan informasi, mengakses informasi, memilih informasi, serta mengevaluasi informasi yang diperoleh melalui internet. Sleain itu dikaji juga secara komprehensif hubunganhubungan antar peubah yang memberikan pengaruh terhadap tinggi rendahnya kinerja karyawan dikaitkan dengan manajemen mutu yang dikaitan dengan tingginya apikasi teknologi. Metode survei cross sectional terhadap pegawai di pemerintahan Kota Tangerang diperoleh hasil bahwa Kompetensi kognitif, afektif dan psikomotor literasi informasi pegawai di lingkungan pemerintahan dapat dikatakan baik. Ada perbedaan yang berarti antara literasi kognitif, afektif dan psikomotor. Kebutuhan infromasi melalui internet sangat dipengaruhi oleh aspek kognitif, afektif dan psikomotor. Akses informasi melalui internet yang dimiliki dikatakan cukup baik dan dipengaruhi oleh tinggi redahnya kompetensi dalam literasi pengetahuan akan teknologi informasi, sikap terhadap informasi melalui internet, serta ketrampilan dalam penggunaan teknologi informasi. Pemilihan informasi yang diperoleh dari internet dilakukan dengan baik oleh pegawai. Pemilihan informasi ini sangat dipengaruhi oleh dua aspek yakni afektif dan psikomotor. Evaluasi terhadap informasi yang diperoleh dalam internet secara umum dianggap penting agar data yang diperoleh valid. Factor evaluasi ini hanya dipengatuhi secara berarti oleh ketrampilan responden dalam menggunakan teknologi infromasi.
\end{abstract}

Kata Kunci: Manejemen, Sumber Daya Manusia, Tekonologi Informatika 
Jurnal Penelitian dan Karya Ilmiah

\begin{abstract}
The purpose of this study is to examine differences in competencies in cognitive, affective, and psychomotor human resources in information technology, to examine the relationship between competencies in information technology and information management; the need for information, access information, choose information, and evaluate information obtained through the internet. The study also comprehensively comprehends the relationships between variables that influence the high and low performance of employees associated with quality management associated with the high application of technology. The cross sectional survey method for employees in the Tangerang City government showed that cognitive, affective and psychomotor competencies in employee information literacy in the government environment could be said to be good. There are significant differences between cognitive, affective and psychomotor literacy. The need for information through the internet is strongly influenced by cognitive, affective and psychomotor aspects. Access to information through the internet that is owned is said to be quite good and is influenced by the high level of competence in the knowledge literacy of information technology, attitudes towards information through the internet, and skills in the use of information technology. The selection of information obtained from the internet is done well by employees. The selection of this information is strongly influenced by two aspects namely affective and psychomotor. Evaluation of information obtained on the internet is generally considered important so that the data obtained is valid. This evaluation factor is only significantly affected by the skills of respondents in using information technology.
\end{abstract}

Keywords: Management, Human Resources, Information Technology

141 I Pelita - Jurnal Penelitian dan Karya Ilmiah 


\section{A. PENDAHULUAN}

Dewasa ini banyak tantangan yang harus dihadapi oleh suatu lembaga atau perusahaan demi membangun perusahaan/lembaga yang berkualitas. Suatu perusahaan dituntut untuk berprilaku efektif dan efisien dalam menjalankan bisnisnya. Apabila tidak demikian, perusahaan tidak dapat bersaing secara kompetitif dengan perusahaan lain yang memiliki kualitas yang lebih baik. Dengan demikian, lembaga atau perusahaan harus selalu menciptakan keunggulan-keunggulan kompetitif yang dapat menjamin keberlangsungan hidup jangka panjang sebuah perusahaan/lembaga.

Werther dan Davis (1996) "menyatakan bahwa sumber daya manusia adalah pegawai yang siap, mampu, dan siaga dalam mencapai tujuan-tujuan organisasi sebagaimana dikemukakan bahwa dimensi pokok sisi sumber daya adalah kontribusinya terhadap organisasi, sedangkan dimensi pokok manusia adalah perlakuan kontribusi terhadapnya yang pada gilirannya akan menentukan kualitas dan kapasitas hidupnya". Dengan begitu faktor utama atau kunci kesuksesan pada perusahaan adalah sumber daya manusia (SDM) yang berkualitas.

Persoalan kebutuhan memperoleh SDM yang unggul dan professional pada abad teknologi informatika tentu memerlukan usaha dan kerja keras dari para manajer, sehingga karyawan dapat bersaing pada era globalisasi yang makin kompetitif. Hal tersebut menurut Sutrisno (2017) "memerlukan reframing, yakni membuka pola pikir baru, sehingga SDM dapat memiliki kompetensi yang sesuai dengan kondisi dan situasi kekinian".

Kompetensi menurut Mc Ashan (Sutrisno, 2017) "mengartikannya sebagai pengetahuan, keterampilan, dan kemampuan yang dikuasai oleh seseorang yang telah menjadi bagian dari dirinya, sehingga ia dapat melakukan perilaku-perilaku kognitif, afektif, dan psikomotorik dengan sebaik-baiknya". Secara lebih rinci Gordon (Sutrisno, 2017) mengemukan bahwa kompetensi sebagai

- $\quad$ Pengetahuan (knowledge), kesadaran dalam bidang kognitif.

- Pemahaman (understanding), kedalaman kognitif

- Kemampuan (skill), sesuatu yang dimiliki oleh individu untuk melaksanakan tugas dan pekerjaan

- Nilai (value), suatu standar perilaku yang telah diyakini dan secara psikologi telah menyatu dalam diri seseorang

- Sikap (attitude), perasaan atau reaksi terhadap rangsangan yang datang

- Minat (interest), kecenderungan seseorang untuk melakukan suatu perbuatan

142 I Pelita - Jurnal Penelitian dan Karya Ilmiah 
Dalam manajemen sumber daya manusia, kompetensi tersebut digunakan sebagai bekal seseorang dalam mencari, meneliti, dan menilai informasi yang digunakan untuk menyelesaikan pekerjaan, sehingga sumber daya manusia mampu menggali potensi sumber daya-sumber daya lain yang dimiliki lembaga atau perusahaan, mampu mengefektifkan dan mengefisiensikan proses produksi dalam lembaga atau perusahaan, serta mampu menghasilkan produk yang memuaskan kebutuhan dan keiinginan konsumen. Akhir dari semua ini adalah memberikan nilai tambah bagi perusahaan atau lembaga dalam bentuk keuntungan daya saing (Sutrisno, 2014).

Dalam era teknologi informasi saat ini, kompetensi tersebut berguna untuk mendefinisikan, mengakses, mengelola, mengintegrasikan, mengevaluasi, menciptakan, serta mengkomunikasikan informasi secara baik dan legal dalam rangka membangun masyarakat berpengetahuan (https://lulufairuz.wordpress.com). Apakah kompetensi-kompetensi yang meliputi aspek kognitif, afektif, serta psikomotor yang dikemukakan oleh Mc Ahsan dan Gordon di atas memberikan kontribusi dalam memanej informasi digital untuk menyelesaikan pekerjaan, dalam hal ini menilai kebutuhan, mengakses, memilih, serta melakukan evaluasi terhadap informasi yang diperole melalui internet? Penelitian ini mencoba untuk menggali informasi tersebut dengan alasan bahwa penggunaan internet dalam penyelesaian pekerjaan sudah menjadi standar di semua lembaga baik pemerintahan maupun swasta. Bulmash (tt) mengatakan bahwa "teknologi masa depan adalah tentang akses cepat ke informasi terkini yang akurat, dan kemampuan untuk mengakses informasi ini melalui berbagai sistem akan memberi organisasi keunggulan strategis".

Marchwka (2013) "mengemukanan bahwa manajemen teknologi informasi adalah proses dimana semua sumber daya yang terkait dengan teknologi informasi dikelola sesuai dengan prioritas dan kebutuhan organisasi. Ini termasuk sumber daya berwujud seperti perangkat keras jaringan, komputer dan orang, serta sumber daya tidak berwujud seperti perangkat lunak dan data. Tujuan utama manajemen teknologi informasi adalah untuk menghasilkan nilai melalui penggunaan teknologi".

Pentingnya inovasi managemen yang berkaitan dengan teknologi informasi dikemukaan oleh Debnat, Sahoo \& Hosain (2018) bahwa manajemen pengetahuan telah berubah menjadi instrumen terbaik yang digunakan oleh perusahaan dalam menjaga keunggulan. Ini adalah kombinasi dari ilmu informasi dan manajemen yang berkaitan dengan efek inovasi untuk keuntungan organisasi dan lembaga instruktif yang berbeda (Su, Lin, 2006). Ini adalah cara yang berubah untuk berurusan dengan 
melihat mengatur, memilah, inisiatif dan mengendalikan bagian-bagian untuk pengembangan manajemen pengetahuan dalam hal kelompok dan menyetujui pandangan anggota yang termasuk dalam proses administrasi (Leung, 2007; Zhao, de Pablos, 2010 dalam Debnat, Sahoo \& Hosain, 2018). Singh et. Al. (Debnat, Sahoo \& Hosain, 2018) menunjukkan bahwa teknologi memiliki konsekuensi penting pada manajemen pengetahuan. Zhang (Debnat, Sahoo \& Hosain. 2018) menyatakan bahwa peningkatan data dan inovasi korespondensi, budaya manusia telah maju ke era informasi.

Pentingnya SDM bebasis teknologi infromasi juga dikemukakan oleh Deloitte (2016) bahwa "SDM harus fokus untuk menarik individu yang cerdas secara digital dan sadar sosial karena mereka adalah kunci bagi organisasi yang akan maju. Jauh lebih mungkin bahwa karyawan yang berpengalaman dengan alat-alat digital seperti media sosial, mobile banking, dan belanja online akan memahami dampak yang mereka dapat terhadap organisasi selama transformasi digital".

\section{B. METODE PENELITIAN}

Penelitian ini bertujuan mengkaji secara komprehensif varaibelvariabel yang mempengaruhi pengaruh kinerja pegawai baik secara internal maupun eksternal yang dikaitkan dengan tingginya aplikasi teknologi, mengkaji secara komprehensif hubungan-hubungan antar variabel yang memberikan pengaruh terhadap tinggi rendahnya kinerja karyawan dikaitkan dengan manajemen mutu yang dikaitan dengan tingginya aplikasi teknologi. Dengan demikian penelitian ini merupakan penelitian kuantitatif. Adapun rancangan strategi kuantitatif yang digunakan dalam penelitian ini adalah survey crosssectional, yakni melakukan pengambilan data pada suatu waktu tertentu dibeberapa tempat.

Populasi dalam penelitian ini adalah pegawai yang bekerja di pemerintahan kota Tangerang. Dengan asumsi bahwa penggunaan teknologi informasi dan komunikasi sudah menjadi bagian dalam aktifitas sehari-hari, maka pengambilan sampel dilakukan dengan acak sederhana, serta ukuran sampel yang diambil yakni sebanyak 97 yang didasarkan pada aturan Gay \& Diehl (1992) bahwa sampel minimal untuk penelitian korelasional minimal 30 responden.

Pengumpulan data dalam penelitian ini dilakukan dengan menggunakan angket. Angket disusun untuk mengukur keseluruhan variabel kompetensi dalam kognitif, afektif, serta psikomotor. Selain itu angket juga digunkaan untuk mengukur bagaimana persepsi responden 
dalam menggunakan teknologi informasi dan komunikasi dalam membantu penyelesaian pekerjaanya. Indikator yang digunaka untuk mengukuranya adalah kebutuhan akan informasi melalui internet, akses penggunaan internet, pemilihan informasi, serta evaluasi terhadap informasi yang dieproleh melalui internet untuk kebutuhan pekerjaan. Sebelum angket digunakan dalam penelitian terlebih dahulu dianalisis untuk mengkaji validitas dan reliabililitasnya. Pengujian ini sebagai bentuk pemenuhan agar instrument yang digunakan dalam penelitian ini merupakan instrument yang mendekati baku, artinya internal validity dari penelitian dapat dipertanggungjawabkan.

Hasil uji coba instrumen yang digunakan dalam penelitian ini adalah sebagai berikut.

Tabel 1. Reliabilitas dan Validitas Item Instrumen Kompetensi

\begin{tabular}{lllllllll}
\hline & \multicolumn{2}{c}{$\begin{array}{l}\text { Validitas } \\
\text { Item }\end{array}$} & \multicolumn{3}{c}{$\begin{array}{c}\text { Validitas } \\
\text { Item }\end{array}$} & \multicolumn{2}{c}{ Validitas } \\
Kognitif & K1 & 0.705 & Afektif & A1 & 0.805 & Psikomotor & P1 & 0.805 \\
\cline { 2 - 9 } & K2 & 0.749 & & A2 & 0.726 & & P2 & 0.777 \\
\hline Alpha $=$ & & & Alpah & & & Alpha & & \\
0.767 & K3 & 0.805 & $=0.820$ & A3 & 0.789 & 0.742 & P3 & 0.710 \\
\cline { 2 - 10 } & K4 & 0.718 & & A4 & 0.723 & & P4 & 0.720 \\
\cline { 2 - 10 } & K5 & 0.660 & & A5 & 0.665 & & & \\
\hline
\end{tabular}

Adapun validitas item masing-masing pengukurannya dapat dilihat dari table berikut.

Tabel 2. Validitas Item Aspek Pengukuran

\begin{tabular}{|c|c|c|c|c|c|c|}
\hline \multicolumn{7}{|c|}{ ASPEK PENGUKURAN } \\
\hline \multicolumn{4}{|c|}{ KEBUTUHAN $($ Alpha $=0.837)$} & \multicolumn{3}{|c|}{ AKSES (Alpha $=0,766)$} \\
\hline K1 & $\mathrm{K} 2$ & K3 & K4 & A1 & A2 & A3 \\
\hline $745^{* *}$ & $.833^{* *}$ & $872^{* *}$ & $.825^{* *}$ & $.866^{* *}$ & $.864^{* *}$ & $.747^{* *}$ \\
\hline \multicolumn{7}{|c|}{ ASPEK PENGUKURAN } \\
\hline \multicolumn{4}{|c|}{ PILIHAN (Alpha $=0,800)$} & \multicolumn{3}{|c|}{$\begin{array}{c}\text { EVALUASI (Alpha = } \\
0,823)\end{array}$} \\
\hline P1 & $\mathbf{P 2}$ & P3 & P4 & E1 & E2 & E3 \\
\hline $.849^{* *}$ & $.839^{* *}$ & $.799^{* *}$ & $.674^{* *}$ & $.902^{* *}$ & $.854^{* *}$ & $.822^{* *}$ \\
\hline
\end{tabular}

**) signifikan pada $\alpha=0,01$ 
Dari hasil analisis terhadap uji coba di atas, maka dapat disimpulkan bahwa keseluruha indicator yang digunakan dalam pengukuran valid dan reliable.

\section{HASIL DAN PEMBAHASAN}

Hasil perhitungan terhadap kompetensi responden dalam dalam aspek kognitif, afektif, maupun psikomotor dalam literasi teknologi informatika terlihat cukup baik, secara rata-rata ketiga aspek tersebut skornya di atas 80 dalam skala 100 . Hasil ini tidak mengherankan jika melihat usia responden dalam penelitian ini, yakni di bawah 50 tahun. Artinya tingkat literasi dapat dipandang baik. Hal ini memperkuat pendapat Lopez, et. al. (Debnat, Sahoo \& Hosain (2018) bahwa kecakapan teknologi berdampak langsung pada perubahan zaman informasi, pertukaran pengetahuan, dan kodifikasi dan penyimpanan pengetahuan. Selain itu Deloitte (2016) juga memberikan rekomendasi pentingnya bahwa SDM fokus untuk literet dalam digital, sadar akan pentingnya pran literasi digital dalam penyelesaian pekerjaan, sehingga perlu mentransformasi diri.

Temuan kedua yang diperoleh adalah adanya pengaruh yang berarti dari kompetensi kognitif/pengetahuan, afektif, dan psikomotor terhadap kebutuhan pegawai dalam mencari infromasi melalui internet. Hal ini ditenadai dengan besarnya model regresi yang menghubungkan ketiga peubah bebas dengan kebutuhan akan informasi sebesar 42,9\%. Selain itu, kesemua variable secara parsial memberikan kontribusi yang sangat berarti, dengan urutan psikomotor, afektif dan pengetahuan. Hasil ini sebagaimana dikemukakan oleh Baran, dkk., 2010) bahwa " the ability to effectively and efficiently comprehend and utilize mass media content". Selanjutnya, Hobbs (1998) "mengungkapkan bahwa tujuan dari media literacy, antara lain: (1) Penguatan akses terhadap informasi; (2) Mendukung dan menumbuhkembangkan lingkungan pendidikan; (3) Menginspirasikan untuk mengembangkan akses terhadap berbagai sumber informasi". Baran, dkk. (2006) mengemukakan beberapa elemen dari media literasi, di antaranya, adalah: (1) An awereness of the impact of media (kesadaran atas dampak media pada individu); (2) An understanding of the process of mass communication (pemahaman pada proses komunikasi massa); (3) Strategies of analyzing and discussing media massages (pengembangan strategi yang digunakan untuk menganalisis dan mendiskusikan pesanpesan media); (4) An understanding of media content as a text that provides insight into our culture and our lives (pemahaman pada konten media sebagai sebuah teks yang memberi wawasan pada kultur dan kehidupan manusia); (5) The ability to enjoy, understand, and appreciate media content (kemampuan 
untuk menikmati, memahami dan mengapresiasi konten media); (6) An understanding of the ethical and moral obligations of media practitioners (memahami tuntutan etika dan moral dari para praktisi media); (7) Development of appropriate and effective production skills (mengembangkan kemampuan-kemampuan produksi secara memadai dan efektif).

Jika ditelaah lebih detail dari koefisien-koefisien pada persamaan regresinya,

$$
\text { KebInfo }=32,553-0,208 \text { Kog }+0,341 \text { Afe }+0,479 \text { Psi }
$$

terlihat bahwa koefisein yang paling besar kontribusinya dalam kebutuhan akan informasi adalah peubah psikomotor, yakni secara parsial memberikan kontribusi sebesar $40,9 \%$, suatu proporsi yang sangat tinggi untuk peran satu varaibel. Model tersebut baik secara keseluruhan maupun parsial menunjukkan sangat berarti dengan p-value keberarrtian keseluruhan modelnya adalah 0,00 , serta untuk parsialnya berturut-turut kognitif, afektif dan psikomotor adalah 0,076; 0,005 dan 0,002. Menjadi menarik adalah aspek kognitif. Tingginya penggunaan teknologi informatika dalam penyelesaian pekerjaan salah satunya ditemukan oleh Alamsyah, Rahayu \& Muslih (2018) "pemanfaatan TI, dan sistem pengendalian internal memiliki pengaruh terhadap kualitas laporan keuangan daerah". Berdasarkan pengujian kontribusi secara simultan oleh variabel-variabel bebas $\left(R^{2}\right)$ sebesar $91,2 \%$. Walaupun perannya sangat bererati namun sifat hubungan yang muncul berkebalikan. Hal ini terlihat dari tanda pada koefisien kognitif yang negative. Hal ini perlu kajian yang lebih mendalam, mengapa penyebab hal tersbeut terjadi.

Peran ketiga aspek pengetahuan, afektif dan psikomotor juga secara bersama memberikan kontribusi yang berarti dalam mengakses informasi. Peran ketiganya secara bersama sebesar $42,4 \%$, serta peran secara individualnya menunjukkan sangat berarti. Adapun modelnya adalah sebagai berikut.

$$
\text { Aksilnfo }=33,481-0,395 \mathrm{Kog}+0,371 \mathrm{Afe}+0,606 \mathrm{Psi}
$$

Sebagaimana diketahui bahwa mengakses infromasi memang membutuhkan kompetensi pengetahuan, namun hal itu tidaklah cukup, sikap punya peran penting dan berarti dalam keiinginan untuk mengakses informasi. Jika seseorang tidak kuat sikap dan kepercayaan dirinya tinggi, maka pengetahuan yang dimilikinya akan sia-sia. Jadi self concept punya peran yang sangat dominan dalam upaya mendorong seseorang untuk mencara dan mengakses informasi melalui internet. Seperti yang dikemukakan oleh Spencer \& Spencer (Sutrisno, 2017) bahwa "sikap dan nilai ini mengukur apa yang dimiliki, apa yang menarik bagi seseorang 
dalam melakukan sesuatu. Misalnya seseorang yang akan menjadi pimpinan seyogianya perlu dinilai apakah memiliki perilaku kepemimpinan sehingga perlu adanya tes tentang leadership ability". Artinya lebih jauhnya apakah ketika dia menyelesaikan masalah manajemen, apakah yakin pencairan informasi akan memberikan solusi.

Jika dilihat kontribusi kompetensi SDM (kognitif, afektif dan psikomotor) terhadap pemilihan informasi, secara keseluruhan ketiganya memberikan kontribusi yang berarti sebesar $45,4 \%$. Model regresi yang menghubungkan antara kompetensi dengan pemilihan informasi adalah sebagai berikut.

$$
\text { PilInfo }=26,406-0,127 \mathrm{Kog}+0,190 \mathrm{Afe}+0,616 \text { Psi }
$$

Jika ditelaah lebih lanjut, peran kompetensi pengetahaun terhadap variabel ini secara statistika tidak menunjukkan kontribusi yang berarti, sehingga model yang terbaiknya adalah sebagai berikut.

$$
\text { PilInfo }=29,671+0,196 \text { Afe }+0,585 \text { Psi }
$$

Pasca dilakukan perhitungan ulang dengan tanpa melibatkan factor kognitif, maka kontribusi dari kedua peubah afektif dan psikomotor memberikan kontribusi sebesar 44,6\%. Penurunan ini 0,8\% sangatlah rasional, karena berkurangnya 1 peubah yang ada dalam model regresi. Temuan ini perlu ditindak lanjuti, mengapa faktor kognitif tidak memberikan peran yang sangat berarti dalam pemilihan informasi. Padahal indicator yang digunakan dalam pemilihan informasi memuat 4 buah, yakni memilih kecocokan infromasi, membaca dengan cepat dalam memilih informasi, mencatat informasi yang dibutuhkan, mengkomunikasi informasi yang diperolehnya. Dari hasil penelaahan terhadap resepon yang diberikan responden, memang sebagian besar keempatnya berada dalam sikap yang ragu dan setuju. Artinya responden belum memiliki sikap pemilihan informasi dengan baik. Artinya bisa saja informasi yang diperolehnya asal sesuai dengan kubutuhan, tetapi tidak dicatat dan dikomunikasikan dengan yang lainnya. Hasil ini sesuai dengan temuan Syarifudin (2014) bahwa sebagain besar masayarakat menggunakan computer atau internet hanya sebagian besar untuk mengolah data, mengolah kata, mengolah angka dan bermain game.

Hasil dari pemilihan informasi di atas sejalan dengan temuan dari evaluasi terhadap informasi. Model regresi yang menghubungkan kompetensi dengan evaluasi informasi adalah sebagai berikut.

$$
\text { EvalInfo }=34,078-0,167 \mathrm{Kog}+0,108 \mathrm{Afe}+0,654 \mathrm{Psi}
$$


Hasilnya factor kognitif dan afektif tidak memberikan kontribusi yang sangat berarti dalam proses menilai informasi yang diperoleh responden dari internet, sehingga model terbaiknya adalah sebagai berikut.

$$
\text { EvalInfo }=25,836+0,628 P \text { si }
$$

Secara keseluruhan ketiga kompetensi memberikan kontribusi dalam evaluasi informasi sebesar 40,4\%. Namun setelah dilakukan analisis lebih lajut, maka diketahui bahwa kompetensi kognitif dan afektif dikeluarkan dari model karena tidak menunjukkan keberartian. Akhirnya peubah evaluasi terhadap infromasi hanya dipengaruhi secara berarti oleh aspek psikomotor, sebesar 38,3\%. Hal ini sangat mungkin dikarenakan tidak semua orang dapat dikatakan ahli tentang infromatika, walaupun mungkin dapat menggunakannya. Karena sebagaimana yang dikemukan oleh Arif, Boy \& Kustini (2013) bahwa profesi informatika sangat khas, menuntut logika tinggi, dan juga etika tinggi (karena jenjang/tingkatan). Dengan catatan, menurut saya, pengguna komputer pada profesi yang "lain" seperti sekretaris, pegawai administrasi, bahkan seorang insinyur sipil yang menggunakan program komputer tidak dapat disebut berprofesi di bidang Informatika.

Hasil ini menunjukkan bahwa responden masih banyak yang tidak melakukan evaluasi terhadap informasi yang diperoleh dari internet disebabkan oleh kompetensi pengetahuan dan sikap mereka. Sangat mungkin bahwa informasi yang diperoleh tidak dicari pembandingnya, apakah informasi awal yang diterima tersebut memuat kesalahan atau tidak. Sikap ini memilih dan menilai infromasi merupakan softskill yang sangat penting dalam menetapkan informasi atau data mana yang akan digunakan dalam penyelesaian pekerjaan. Dengan demikian, perlu ada upaya pemahaman yang komprehensif dari sumber daya manusia suatu lembaga apabila pengolahan manajemen di lembaga tersebut sudah berbasis teknologi informasi, teritama internet. Hasil ini dapat menjadi bukti dari hasil penelitian dari Suhaya, dkk. (2017) bahwa "pola pengembangan kinerja pegawai untuk peningkatan produktivitas kerja sering kali lebih banyak diarahkan pada peningkatan kompetensi pegawai dalam bidang kogntif dan ketrampilan. Padahal tinggi rendahnya produktivitas kerja ditentukan oleh sikap, seperti kepuasan kerja dan motivasi kerja, serta faktor eksternal, yakni budaya organisasi yang diciptakankan oleh pimpinan, serta lingkungan kerja dimana pegawai tersebut bekerja". 
Hasil analisis di atas memperkuat pendapat Auriol dan Sexton (2001) bahwa Istilah "skill atau keterampilan" mengacu pada kualifikasi yang diperlukan untuk melakukan tugas-tugas tertentu di pasar tenaga kerja. Dalam arti yang paling umum, ini mencerminkan tingkat modal manusia di pasar tenaga kerja. Istilah "peningkatan kemampuan" dapat dilihat sebagai identik dengan pengembangan sumber daya manusia. Keterampilan bersifat multidimensi, karena sebagian besar pekerjaan membutuhkan banyak dari mereka untuk melakukan tugas secara memadai, mulai dari kemampuan fisik seperti koordinasi mata-tangan, ketangkasan dan kekuatan, hingga kognitif (penalaran analitik dan sintetik, kemampuan numerik dan verbal) dan antarpribadi (pengawasan), kepemimpinan, keterampilan (Wolff dalam Auriol dan sexton, 2001).

\section{KESIMPULAN DAN REKOMENDASI} berikut.

Kesimpulan yang diperoleh dari hasil penelitian ini adalah sebagai

- Kompetensi kognitif, afektif dan psikomotor literasi informasi pegawai di lingkungan pemerintahan dapat dikatakan baik.

- Ada perbedaan yang berarti antara literasi kognitif, afektif dan psikomotor.

- Kebutuhan infromasi melalui internet sangat dipengaruhi oleh aspek kognitif, afektif dan psikomotor.

- Akses informasi melalui internet yang dimiliki dikatakan cukup baik dan dipengaruhi oleh tinggi redahnya kompetensi dalam literasi pengetahuan akan teknologi informasi, sikap terhadap informasi melalui internet, serta ketrampilan dalam penggunaan teknologi informasi.

- Pemilihan informasi yang diperoleh dari internet dilakukan dengan baik oleh pegawai. Pemilihan informasi ini sangat dipengaruhi oleh dua aspek yakni afektif dan psikomotor.

- Evaluasi terhadap informasi yang diperoleh dalam internet secara umum dianggap penting agar data yang diperoleh valid. Factor evaluasi ini hanya dipengatuhi secara berarti oleh ketrampilan responden dalam menggunakan teknologi infromasi. 
Adapun dari hasil penelitian ini direkomendasikan bahwa:

- Perlu adanya peningkatan kompetensi pegawai dalam teknologi informasi, pemahaman terhadap informasi yang diperoleh melalui internet yang memerlukan pemilihan dan penilaian melalui perbandingan dengan data dari sumber yang berbeda, serta ketrampilan dalam penggunaan teknologi informasi.

- Aspek kogntif memiliki hubungan yang berkebalikan dengan keempat respon, kebutuhan informasi, akses terhadap informasi, pemilihan dan penilaian informasi, untuk itu diperlukan penelitian untuk mengkaji lebih komprehensif factor-faktor penyebabnya.

- Secara teori sikap memiliki peran dalam mendorong motivasi untuk memperoleh infromasi yang dibutuhkan, mencari akses, memilih dan mengevlasui. Nanum temun dalam penelitian ini aspek sikap tidak memberi kontribusi yang berarti dalam evalausi informasi. Perlu kajian yang mendalam, apakah hal ini akan memunculkan penggunaan informasi yang tidak tepat dan atau salah.

\section{Referensi}

Alamsyah, M. R., Rahayu, S., \& Muslih, M. (2018). Kompetensi Sumber Daya Manusia, Penerapan Sistem Akuntansi Keuangan Daerah (Sakd), Pemanfaatan Teknologi Informasi, dan Sistem Pengendalian Internal terhadap Kualitas Laporan Keuangan Daerah (Studi Empiris pada Satuan Kineja Perangkat Daerah (Skpd) Kota Depok. Majalah Ilmiah UNIKOM Vol. 15 No 2. Tersedia :https://jurnal.unikom.ac.id/jurnal/kompetensi-sumberdaya.6y/6.miu-15-no-2-m.rifky.pdf.

Arif, S. N., Boy, A. F., \& Kustini, S. (2013). Menakar Harga Sumber Daya Manusia Bidang Informatika dalam Era Informasi. Jurnal SAINTIKOM Vol. 12, No.2, Mei 2013. Tersedia: https:// prpm.trigunadharma.ac.id/public/fileJurnal/hp0oJurnal \%2012-2-2013\%20Saiful_5.pdf.

Ariol, L., \& Sexton, J. (2001). Human Resources in Science and Technology: Measurement Issues and International Mobility. Tersedia: http//www.ricyt.orgfilesM_Schaper.pdf.

Armstrong. (1999). The Art of HRD: Human Resource Managemet, London: Crest Publishing House.

Ardana, I. K. (2012). Manajemen sumber daya manusia. Yogyakarta: Graha Ilmu. 
Bulmash, J. (tt). Human Resources Management and Technology. Tersedia: http://www.catalogue.pearsoned.caassetshipcahip_ca_pearsonhi gheredsamplechapter0132270870.pdf.

Debnat, G. C., Sahoo, M., \& Hosein, M. I. (2018). Knowledge Management in Technological Era: A Managerial Perceptive. International Journal of Mechanical Engineering and Technology (IJMET) Volume 9, Issue 6, June 2018, pp. 83-91, Article ID: IJMET_09_06_011. Tersedia: http://www.iaeme.com/IJMET/issues.asp?JType=IJMET\&VType= 9\&IType $=6$ ISSN Print: 0976-6340 and ISSN Online: 0976-6359.

Delloite. (2016). The changing role of people management in the digital age. Tersedia: https://www2.deloitte.comcontentdamDeloittexe Documentshuman-capitaldme_hc_changing_role_of_people_ management_in_the_digital_era.pdf.

Dessler, G. (1997). Manajemen sumber daya manusia, PT. Prenhallindo, Jakarta. Indraswari, I. (2011). Pengaruh budaya organisasi dan motivasi terhadap kepuasan kerja dalam mempengaruhi kinerja karyawan kantor unit PT. Ttelkom regional IV Semarang. Skripsi Program Sarjana Fakultas Ekonomi Universitas Diponegoro. Tidak diterbitkan. Tersedia: eprints.undip.ac.id/29903/1/Skripsi004.pdf.

Jonathan, H., dan Westover. (2014). Strategic human resource management. USA: HCI Press.

Schuler, R.S., Dowling, J.P., Smart., and Huber, V. L. (1992) Human resource management in Australia (2nd edn) Sydney: Harper Educational.

Slocum, J. W., \& Hellriegel, D. (2007). Fundamental of organizational behavior. Australia: Thomson-South Western.

Sihite, M. (2018). Peran kompetensi dalam mewujudkan sumber daya manusia yang berdaya saing tinggi di era revolusi industri 4.0: suatu tinjauan konseptual. Jurnal Ilmiah Methonomi. p-ISSN: 2460562X Volume 4 Nomor 2 (2018) e-ISSN: 2598-9693. Tersedia: www.methonomi.net.

Silverthorne, C. (2004). The impact of organizational culture and personorganization fit on organizational commitment and job satisfaction in Taiwan. Leadership \& Organization Development Journal. Vol. 25, 7/8; ABI/INFORM Global, p. 592.

Simamora, H. (1997). Manajemen sumber daya manusia, Yogyakarta; STIE YKPN.

Suhaya, dkk. (2017). Analisis Budaya Organisasi, Lingkungan Kerja, Motivasi Kerja, Kepuasan Kerja, dan Kinerja Pegawai (Studi di Badan Pendapatan Daerah Kabupaten Tangerang). Laporan Penelitian. LPPM-UNIS (Tidak dipublikasikan). 
Susetyo, W.E. (2014). Pengaruh budaya organisasi dan lingkungan kerja terhadap kepuasan kerja dan kinerja karyawan pada pt. bank muamalat indonesia divisi konsumer area cabang Surabaya .Jurnal Ilmu Ekonomi \& Manajemen, Vol. 1 No.1. hal. 83 - 93.

Sutrisno, E. (2009). Manajemen sumber daya manusia. Jakarta: Prenadamedia Group.

Syarifudin. (2012). Teknokrasi: Kenapa PNS Tidak Produktif?. Tersedia: alfanaini. blogspot.com /2012/01/kenapa-pns-tidakproduktif.html.

Syarifudin. (2014). Literasi Teknologi Informasi dan Komunikasi. Jurnal Penelitian Komunikasi Vol. 17 No.2, Desember 2014: 153-164. Tersedia: https://www.Literasi_Teknologi_Informasi_dan_Komunikasi.pdf

Tiffin, J., \& Cormick, E. J. (1958). Industrial Psycology. Japan: Morusan Co. Ltd.

Terry, G. R., dan Rue L. W. (1992). Dasar-dasar manajemen. Jakarta: Bumi Aksara.

Vecchio, R. P. (1995). It's not easy being green: Jealousy and envy in the workplace. In G.R. Ferris (Ed.), Research in Personnel and Human Resources Management, 13 (pp-201-244). Greenwich, CT: JAI Press.

Warsito, B. (2015). Pengaruh organisasi dan lingkungan kerja terhadap organizational citizenship behavior, motivasi dan kerja. Jurnal Ekonomi Moderenisasi, Volume 4. Hal 84.

Werther, W. B., dan Davis, K. (1996). Manajemen personalia dan sumber daya manusia, Erlangga, Jakarta.

Widodo, D. S. (2014). Influence of leadership and work environment to job satisfaction and impact to employee performance (Study on Industrial manufacture in West Java). Journal of Economics and Sustainable Development, Vol.5, No.26. Page 63-64.

Website:

http://www. digilib.unila.ac.id/16557/13/BAB\%20I.pdf

http://www.landasanteori.com/2015/10/

http: //www.digilib.unila.ac.id/14022/16/BAB\%20II.pdf

http://www.uin-suska.ac.id40624BAB\%20II.pdf. 